\title{
INVOLVEMENT OF PSYCHIATRISTS IN NURSE EDUCATION
}

The Nursing Sub-Committee of the Education Committee was asked by the General Nursing Council for information concerning the attitude of psychiatrists towards involvement in the training of nurse learners. In order to gather information a questionnaire was circulated to members of the College requesting information about their knowledge of visits by General Nursing Council Inspectors and their awareness of the implications of the report issued by the Inspector concerning nursing services.

The response rate was disappointing, but it must be recognized that those who did respond were presumably interested in nurse training while for the remainder it was either irrelevant or of no interest. Two hundred and seventy-two replies were received in all, 231 from England and Wales, 35 from Scotland and six from other countries. I am most grateful to all those who did respond.

\section{England and Wales}

Thirty-eight per cent of respondents had knowledge of the most recent General Nursing Council visit of inspection. Two-thirds of these were working in Adult Mental Illness and equal numbers of the remainder in Child and Adolescent Psychiatry or in Mental Handicap. Almost all of those who knew of the visit were members of Area, District or other Administrative Committees. Twenty-nine (13 per cent of the psychiatrists) actually met the Inspector at the time of their visit.

\section{Scotland}

The figures for Scotland were substantially smaller, with only 35 replies, but half of these knew of the visit of the Inspector, the majority of these being in the field of Adult Mental Illness. Almost all of those who knew were on various Administrative Committees.

Many psychiatrists made additional comments, the general tone of these being a willingness to be more actively involved in nurse education. There was a feeling that there had been increasing separation between doctors and nurses, and this was regretted. Many reported giving formal lectures but felt that they did not participate in the general educational activities of the learners. It should be pointed out that a few psychiatrists were obviously actively involved in nurse education and played an important role not only in lecturing but by means of seminars, case presentations and discussion groups; unfortunately, these appeared to be the exception rather than the rule.

C. P. SeAger

\section{OUR COLLEGE SECRETARY}

\section{'Twenty years a-growing'}

It is 20 years since Natalie Cobbing entered the service of the RMPA as its Secretary. She embarked on her duties in the Dickensian ambience of the old headquarters at 11 Chandos Street, where she and a single assistant tried to attend to the whole business of Council, Committees, and Annual, Quarterly, Sectional and Divisional meetings. New Presidents arrived after every Annual Meeting, their opinions and expectations differed and their personal style of leadership and administration had to be catered for.

Natalie Cobbing lived and worked through the move to the more spacious surroundings of Chandos House and the period of new challenges that were looming up for the Association: the campaign to form a Royal College, the conflicts within our organization and the obstacles that appeared at every stage of the journey.

Moreover, during that time the management of the Journal and of the Association's finances began to be undertaken at headquarters.

Then, when in 1971 the Charter finally materialized there was the College's new Council, Court of Electors and Committees to be set up and the Membership Examination to be established. Under a threat of eviction when the lease on
Chandos House ended in 1972, we managed almost at the last moment to purchase 17 Belgrave Square.

In such an upheaval, and in face of a seemingly crippling debt and predictions of ruin, it required steady nerves and devotion in abundance to assist morale and to keep the organization of the College intact and its work moving. Natalie Cobbing's unflagging efforts and her sound practical judgement made a contribution of the greatest value at this time. She has brought to the task an unusual flair for organization. The office for two has evolved into the present administrative structure with its separate departments and a staff of around 25 . Her life has been identified with that of the College, and the loyalty and undimmed enthusiasm she has inspired has led others to emulate her example. Her keen intelligence, clarity of thought and retentive memory have eased the way of Officers and Committees of the Association and College.

She has placed both present and future generations of psychiatrists in her debt, and we gladly pay tribute to the dedicated and ungrudging service she has rendered us over 20 years.

MARTIN ROTH 